\title{
Change in Fire Frequency During the Last 300 Years in the Eastern Canadian Boreal Forests.
}

\author{
Daniel Lesieur1, Yves Bergeron1, Sylvie Gauthier 2, Victor Kafka², Patrick Lefort1 \\ 1 Groupe de Recherche en Écologie Forestière interuniversitaire and Chaire industrielle en aménagement forestier durable, Université du \\ Québec à Montréal; lesieur.daniel@uqam.ca; bergeron.yves@uqam.ca; c1000@er.uqam.ca (Lefort) \\ 2 Laurentian Forestry Centre, Natural Resources Canada, Canadian Forest Service; sgauthier@cfl.forestry.ca; victor_kafka@pch.gc.ca
}

There is little doubt that climate changes cause changes in forest disturbances, including natural fire regimes. Several local records from both the western and eastern parts of Canada suggest that a major decrease in fire frequency (i.e. area burnt per year) occurred alongside climatic warming at the end of the Little Ice Age around 1850. To assess the degree to which this was a general phenomenon in the boreal forest of eastern Canada, we have reconstructed fire frequency for the last 300 hundred years over an area covering more than 30000 $\mathrm{km}^{2}$ along a $1000-\mathrm{km}$ long transect from eastern Ontario (80 $\left.30^{\circ} \mathrm{W}\right)$ to central Québec $\left(73^{\circ} 30^{\circ} \mathrm{W}\right)$ between 48 and $50^{\circ}$ north (Fig. 1, Table 1). With the exception of the southern part of the Abitibi-West region, which was colonized for agriculture in the beginning of the twentieth century, the area is essentially unpopulated and is typical of the eastern boreal forest. The area is currently under extensive forest management.

\section{Fire history reconstruction}

Three lines of evidence were used to map the distribution of forest

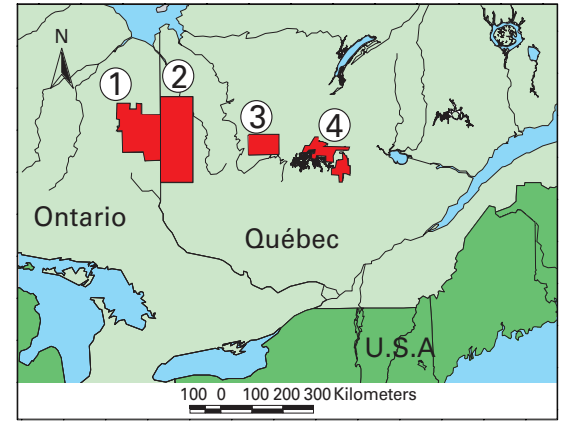

Fig. 1: Location of the four study areas. 1) Lake Abitibi Model Forest; 2) Abitibi-West; 3) Abitibi-East; and 4) central Québec

stands as a function of time since the last fire:

- Historical maps and documents (from forest companies, protection agencies)

- Old aerial photographs (1920s and 1930s)

- Standard dendrochronological techniques

The length of the reconstruction was therefore limited by tree Iongevity.

\section{Forest Age Distribution and Fire Cycles}

The mean age of stands and the high percentages of forest older

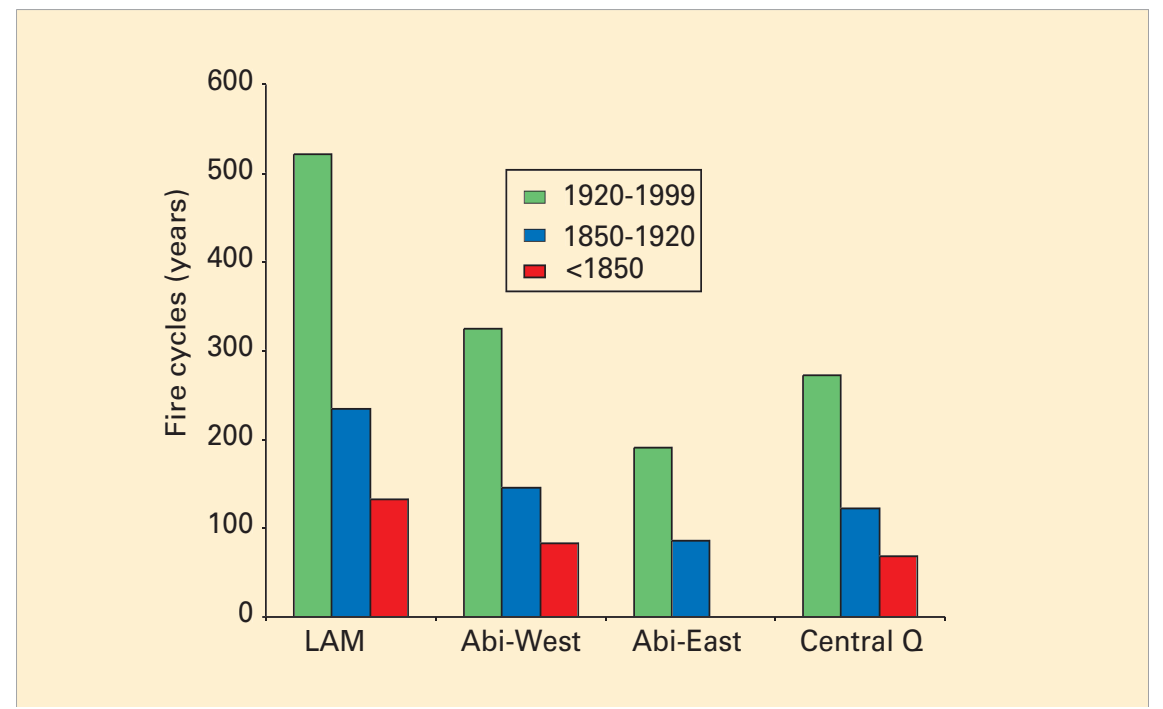

Fig. 2: Fire cycles for each region: 1) Lake Abitibi Model Forest (LAM); 2) Abitibi-West (Abi-West); 3) Abitibi-East (Abi-East); and 4) Central Québec (Central Q).

than 100 years (Table 1) indicate a low proportion of current stands which grew up following fires more recent than 1920. The average stand age decreases from the westernmost study area (172 years) to the eastern region (111 years). There is a slight increase in central Québec (127 years) (Table 1).

Fire cycles were computed for three predefined time periods (before 1850, 1850-1920 and after 1920; Fig. 2). The 1850 limit was selected because it corresponds to the end of the Little Ice Age in the area (Archambault and Bergeron 1992), while 1920 corresponds to the beginning of the intensive colonization. Throughout the transect, a substantial decrease in fire cycle is observed over time with shorter fire cycles (69-132 years) before 1850 increasing to more than 190 years after 1920 (Fig. 2).

\section{Change in Fire Frequency} Triggered by Climate Change Fig. 3 indicates the global cumulative time since the last fire disturbance. Since none of the relationships are straight lines, they suggest that fire frequency has changed over time. Each relationship indicates a change in the slope in the early $20^{\text {th }}$ century and around the mid $19^{\text {th }}$ century (vertical lines in Fig. 3). The western part (LAM) is characterized by a fire frequency that is significantly longer than in the other regions, whereas the shortest fire frequency length is observed in the eastern part (Abitibi-East).

Since the areas examined were still untouched in 1850, the decreasing fire frequency observed probably was not caused by direct human activity. Although the influence of native people on fire frequency can not be totally ruled out, we believe that the low population density in this part of the boreal forest rules out human ac- 


\section{Science Highlights}

Table 1. Characteristics and estimated fire cycles for each region.

\begin{tabular}{|c|c|c|c|c|c|c|}
\hline \multirow[t]{2}{*}{ Region $^{3}$} & \multirow{2}{*}{$\begin{array}{l}\text { Area } \\
\left(\mathrm{km}^{2}\right)\end{array}$} & \multirow{2}{*}{$\begin{array}{c}\text { Mean age } \\
(y r)\end{array}$} & \multirow{2}{*}{$\begin{array}{c}\text { over } 100 \mathrm{yr} \\
(\%)^{1}\end{array}$} & \multicolumn{3}{|c|}{ Fire cycles $(y r)^{2}$} \\
\hline & & & & 1920-1999 & $1850-1920$ & $<1850$ \\
\hline Lake Abitibi Model Foresta & 8245 & 172 & 78 & $521(370-733)$ & $234(171-321)$ & 132(98-178) \\
\hline Abitibi-West ${ }^{b}$ & 15793 & 139 & 57 & $325(248-424)$ & $146(114-187)$ & $83(65-105)$ \\
\hline Abitibi-Eastc & 3294 & 111 & 54 & $191(124-294)$ & $86(56-131)$ & ------ 4 \\
\hline Central Québec ${ }^{b, c}$ & 3844 & 127 & 56 & $273(183-408)$ & $123(83-181)$ & $69(47-102)$ \\
\hline
\end{tabular}

1 Percentage of the stands that are older than 100.

2 The three periods are significantly different at $p<0.001$, in all regions.

${ }^{3}$ Regions marked with different letters are significantly different at $p<0.05$ for the fire cycles of the three periods.

${ }^{4}$ There was not enough data to allow for fire cycle computation for this period.

tivities as an explanation of the observed decrease. The subsequent decrease in fire frequency around 1920 corresponds to a period of important human settlement, especially in the southern section of the study area and may therefore have resulted from human activities such as passive and active fire suppression. However, it is difficult to explain the observed decrease as solely due to anthropogenic effects. Active suppression using water bomb tankers began only around 1970. Fire danger reconstitution studies suggest that there was a decrease in the duration and/ or magnitude of the fire season in the study area during the $20^{\text {th }}$ century. Furthermore, the pattern during the 300-year period is also similar to that reported for the islands of Lake Duparquet (Bergeron 1991), where fires have never been suppressed. Taken together, these factors suggest that the decrease in fire frequency is at least partly driven by a change in climate. The decrease in fire cycle at Lake Duparquet has been shown to be related to a reduction in the frequency of drought events since the end of the Little Ice Age (Bergeron and Archambault 1993). The present results suggest that this phenomenon can be extended to a larger area of the eastern boreal forest. It is hypothesized that the warming that started at the end of the Little Ice Age was accompanied by a change in the circulation of air masses and consequently the drought regime. This is supported by simulations using the Canadian General Atmospheric Circulation Model, which predicted a decrease in forest fire activity for most of the eastern boreal forest, in the event of future warming (Flannigan et al. 1998).

On the other hand, the increase in fire frequency from west to east does not seem to be related to a similar trend in the severity of climatic conditions. In fact, precipitation and computed fire weather indices suggest a decrease in the severity of the fire season from west to east (Kafka et al. unpublished results). This suggests that non-climatic factors such as lightning occurrences could influence the fire regimes in these areas. The longer fire cycles observed in eastern Ontario and western Québec might be explained in part by the abundance of wetlands that characterized the region as compared to the eastern portion of the study area, located on the Canadian Shield. Currently it is not possible to discriminate between the relative importance of climatic ver-

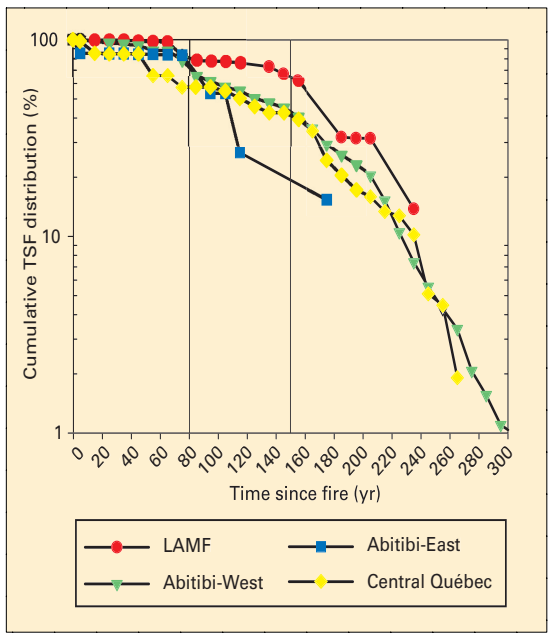

Fig. 3: Semilog cumulative time since fire (TSF) distribution for each of the sectors. Since distributions did not show a constant hazard of burning, fire cycles were computed for periods of relatively constant fire frequency (see Table 1 for the results). sus geological characteristics as controls on fire frequency.

\section{Conclusion}

Our results show that there is considerable spatial and temporal variation in fire cycles along a east-west transect in the boreal forest of northeastern Canada. In all of the four studied regions, there has been an increase in the fire cycle period since the end of the Little Ice Age around 1850. Climate change, though not the only factor involved, seems to have played a role in the spatial and temporal variability of fire frequency (see Bergeron et al. 2001). The fire cycles reported here are longer than those generally reported for the boreal forest. Our results indicate that fire frequency is highly variable in time and space, results that are consistent with other studies. These temporal and spatial variations suggest that fire in the boreal forest is a complex process.

\section{REFERENCES}

Archambault, S. and Bergeron, Y, 1992, An 802-year tree-ring chronology from the Quebec boreal forest, Can. J. For. Res., 22, 674-682.

Bergeron, Y. 1991, The influence of island and mainland lakeshore landscapes on boreal forest fire regimes, Ecology, 72, 1980-1992.

Bergeron, Y. and Archambault, S., 1993, Decrease of forest fires in Quebec's southern boreal zone and its relation to global warming since the end of the Little Ice Age, Holocene, 3, 255-259.

Bergeron, Y., Gauthier, S., Kafka, V., Lefort, P. and Lesieur, D., 2001, Natural fire frequency for the eastern Canadian boreal forest: consequences for sustainable forestry, Can. J. For. Res., 31, 384-391.

Flannigan, M., Bergeron, Y., Engelmark, 0. and Wotton, M., 1998, Future wildfire in the northern forests: Less than global warming would suggest. J. Veg. Sci., 9, 469-476. 